\title{
Pessoas com deficiência moradoras de bairro periférico da cidade de Sáo Paulo: estudo de suas necessidades
}

\author{
Marta Aoki ${ }^{a}$, Fátima Correa Oliver ${ }^{b}$ \\ ${ }^{a}$ Mestre em Ciências e Terapeuta ocupacional do Departamento de Fisioterapia, Fonoaudiologia e Terapia \\ Ocupacional, Faculdade de Medicina da Universidade de São Paulo - FMUSP, São Paulo, SP, Brasil \\ 'Professora Doutora, Docente do Departamento de Fisioterapia, Fonoaudiologia e Terapia Ocupacional, \\ Faculdade de Medicina da Universidade de São Paulo - FMUSP e do Programa de Pós-graduação em Terapia \\ Ocupacional da Universidade Federal de São Carlos - UFSCar, São Paulo, SP, Brasil
}

\begin{abstract}
Resumo: Este estudo apresenta as demandas e necessidades de saúde de pessoas com deficiência que participaram de um grupo de convivência, realizado em parceria entre serviço de atenção primária à saúde, universidade e centro comunitário. Compreendeu-se necessidade de saúde como um fenômeno relacionado a formas de produção e reprodução dos diferentes grupos sociais e que podem ser identificadas a partir do reconhecimento dos modos de trabalhar, de consumir, de viver, de se relacionar e das características do território. Participaram do grupo dez adultos com deficiências, moradores de bairro periférico, sendo 6 mulheres e 4 homens. Cinco deles apresentavam deficiência intelectual; 3 deficiência física e 2 deficiências múltiplas. Foram realizadas entrevistas semiestruturadas com questões sobre as atividades cotidianas, experiências em saúde e reabilitação, educação, trabalho e participação comunitária; foram 5 entrevistados participantes do grupo, que o representavam em termos de idade, sexo e tipo de deficiência. Estudar, realizar tratamento em reabilitação, ter uma moradia digna, alimento, trabalho, benefício previdenciário, deslocar-se, passear e conversar foram as principais demandas apresentadas. Necessidades histórica e socialmente determinadas situam-se entre a natureza e a cultura dos sujeitos e dizem respeito não apenas à manutenção da vida, mas também à realização de um projeto de vida em que a pessoa acessa direitos sociais. Porém, as necessidades dessas pessoas expressaram também a vivência de processos de exclusão social. Alternativas assistenciais em reabilitação podem ser implementadas por profissionais da saúde a partir das necessidades relatadas pelas pessoas com deficiência e suas famílias, articuladas aos recursos assistenciais e comunitários existentes.
\end{abstract}

Palavras-chave: Pessoas com Deficiência, Reabilitação, Participação Comunitária, Terapia Ocupacional, Necessidades.

\section{Disabled people from the outskirts of Sáo Paulo: a study of their needs}

\begin{abstract}
In this study, it is showed the health demands and needs of people with disabilities who participated in a support group conducted in partnership with primary health care service, university and community center. We understand health needs as phenomena related to forms of production and reproduction of different social groups that can be identified by the recognition of different ways of working, consuming, living, and relating, as well as by the characteristics of the territory. Ten adults with disabilities participated in the group: six women and four men, all residents of a peripheral neighborhood of the city. Five of them presented intellectual disability, three were physically disabled, and two showed multiple disabilities. We conducted semi-structured interviews comprising questions on daily life activities, experiences in health and rehabilitation, education, work and
\end{abstract}

Autor para correspondência: Marta Aoki, Faculdade de Medicina da Universidade de São Paulo, Rua Cipotânea, 51, Cidade Universitária, CEP 05360-160, São Paulo, SP, Brasil, e-mail: aoki@usp.br

Recebido em 10/2/2012; Revisão em 12/8/2012; Aceito em 1/3/2013 
community participation, with five members of the group, who were representative in terms of age, gender and disability. Studying; performing rehabilitation treatment at home; having adequate housing, food, employment, and social security benefits; being able to move, go out, and have conversations were the main needs presented. Historically and socially determined needs are part of both nature and culture of these individuals and relate not only to maintaining life, but also to the realization of a life project in which a person can have access to social rights. However, those people's needs also reflect their experience of social exclusion processes. Alternative care in rehabilitation can be implemented by health professionals based on the needs reported by people with disabilities and their families, who take active participation in existing community resources and assistance.

Keywords: People with Disabilities, Rehabilitation, Community Participation, Occupational Therapy, Needs.

\section{Introdução}

Neste artigo é apresentada parte dos resultados de um estudo (AOKI, 2009) sobre necessidades de pessoas com deficiência, moradoras de região periférica da cidade de São Paulo, que participaram de um grupo de convivência na comunidade realizado por um serviço de atenção primária à saúde (APS).

Conhecer as demandas e necessidades dessas pessoas possibilita elaborar estratégias de intervenção que dialoguem com sua condiçáo de vida e com os recursos comunitários existentes, com o intuito de favorecer o acesso aos cuidados de saúde e reabilitação.

Considera-se que o serviço de APS é um importante campo de práticas assistenciais às pessoas com deficiência, conforme indica a Portaria n. 793, que institui a Rede de Cuidados à Pessoa com Deficiência no âmbito do Sistema Único de Saúde (BRASIL, 2012) e prevê a atenção integral à saúde da pessoa com deficiência, nos diversos níveis de complexidade e especialidades, compreendendo a unidade básica de saúde (UBS) como o lugar privilegiado para o atendimento dessa população. Essa iniciativa vem compor, juntamente com os Núcleos de Apoio à Saúde da Família - NASF (BRASIL, 2010), alternativas para desenvolvimento e ampliação da cobertura assistencial de pessoas com deficiência no país.

Os NASF têm como objetivo subsidiar a Estratégia de Saúde da Família, sendo a reabilitação uma das áreas de atuação dos profissionais que o integram. Pela proximidade geográfica e sociocultural com a comunidade, o serviço local de saúde deve estar apto a oferecer atendimento resolutivo também para as demandas e necessidades apresentadas pelas pessoas com deficiência.

Compreende-se necessidade de saúde como um fenômeno complexo, relacionado a formas de produção e reprodução dos diferentes grupos sociais, vinculado a múltiplas dimensôes da realidade (EGRY; OLIVEIRA, 2008). Essas necessidades podem ser identificadas pelo reconhecimento das formas de trabalhar, de consumir, de viver, de se relacionar e das características do território onde se vive, que também determinam o processo saúde-doença mediado pelas condições materiais da vida cotidiana, diferenças de classes sociais, concentração de renda e poder pelas classes dominantes (CAMPOS; BATAIEIRO, 2007).

Nesse sentido, é necessário pontuar a diferença entre necessidade e demanda de saúde, que é compreendida como uma busca ativa por intervenção que representa também consumo, no caso dos serviços (SCHRAIBER; MENDES-GONÇALVES, 1996, p. 29). Essa procura é motivada pelo carecimento, algo que a pessoa perceba que deve ser corrigido, pois lhe traz sofrimentos, sentimento de ausência e implicações para o cotidiano. Para os autores, a pessoa que sente determinada carência procura meios de amenizá-la, a partir dos seus conhecimentos prévios sobre possíveis soluçóes. O resultado das intervençôes sobre qualquer carência é reconhecido como necessidade, tornando as próprias intervençóes também novas necessidades. A solução produzida e distribuída por algum serviço poderá responder às necessidades, mas também será um contexto de criação de necessidades, como se pode observar pela constituição da rede de atenção em saúde. Ainda, para esses autores, o problema está colocado quando é apenas uma parte restrita da população (gestores), que irá definir quais são as necessidades sociais (de todos) e quais serão as respostas oferecidas. Nesse processo, corre-se o risco de ignorar as desigualdades das necessidades sociais, compreendidas como carências criadas na vida em sociedade.

A adoção de uma tipificação de necessidades de saúde, como proposta por Cecílio (2001), também pode auxiliar sua compreensão. $\mathrm{O}$ autor fundamenta sua discussão sobre necessidades na apresentação de quatro grandes conjuntos: necessidade de boas condiçôes de vida; garantia de acesso à tecnologia para manutenção e prolongamento da vida; vinculaçáo com profissionais de saúde e com equipe, bem como 
a necessidade de autonomia nas escolhas e decisóes sobre o modo de vida e de realização do autocuidado.

$\mathrm{O}$ estudo da literatura estrangeira sobre a assistência às pessoas com deficiência na APS apresenta discussóes principalmente relacionadas à falta de acesso a serviços de saúde (BAXTER et al., 2006; EASTGATE; LENNOX, 2003; JANG et al., 2006). Nesses estudos, destacam-se também as lacunas nos processos assistenciais de pessoas com deficiências graves e severas no contexto da APS (JANG et al., 2006) e a falta de um trabalho preventivo, por exemplo, de identificação precoce de morbidades em adultos com deficiências intelectuais (BAXTER et al., 2006).

$\mathrm{Na}$ literatura nacional, há estudos sobre as contribuiçôes da terapia ocupacional na assistência às pessoas com deficiência no âmbito da APS (ROCHA; SOUZA, 2011). Em estudo sobre a assistência às pessoas com deficiência na APS, Othero e Dalmaso (2009) entrevistaram trabalhadores de um centro de saúde escola e identificaram que, para eles, os principais focos de intervenção seriam o cuidado corporal, a orientação de cuidadores e as condiçóes de moradia. Ressaltaram também o papel do serviço de saúde como um contexto instaurador de necessidades, voltado principalmente para as questóes clínicas, com poucas repercussôes de demandas para fomento da participaçáo social e acesso a direitos. Em outro estudo, Othero (2010) identificou demandas e necessidades de saúde de pessoas com deficiência, a partir da óptica dos sujeitos, e revelou que as necessidades incluem aspectos específicos da assistência à saúde e reabilitação e englobam outras dimensóes, como o acesso a direitos, ao trabalho e ao lazer, e a importância de açôes interdisciplinares e intersetoriais no sentido de sua garantia.

Sabe-se também que existe uma circularidade entre necessidades de saúde e processos de trabalho (PEDUZZI; SCHRAIBER, 2009), na qual a finalidade do trabalho é o aprimoramento das necessidades humanas, que, se atendidas, têm o potencial de aperfeiçoar a existência humana no sentido de produzir sujeitos mais criativos e autônomos (CECÍLIO, 2001).

Assim, a partir das concepçôes de demandas e necessidades de saúde apresentadas, consideram-se insuficientes as intervençóes em saúde e reabilitação que privilegiam o desenvolvimento ou o restabelecimento de funçóes (motoras, cognitivas e/ou sensoriais), pois estas podem desconsiderar importantes fatores pessoais, familiares e do contexto sociocultural na constituição e compreensão das necessidades das pessoas com deficiência e de seus familiares e portanto também no desenvolvimento de alternativas assistenciais.

\section{Material e métodos}

Este estudo se insere no campo das pesquisas qualitativas por se tratar da compreensão e reflexão sobre as necessidades percebidas pelas pessoas com deficiência, tradicionalmente com poucas oportunidades de se expressar sobre esses temas.

As necessidades de saúde, compreendidas como necessidades de reprodução social, foram abordadas a partir da compreensão do modo de vida dos participantes, suas formas de viver, trabalhar, consumir e relacionar-se socialmente. Para tanto, foi utilizada a entrevista semiestruturada conduzida por uma das autoras com experiência de assistência junto aos participantes, o que facilitou o contato interpessoal. A entrevista abordou a situação de saúde, experiências em reabilitação, educação e trabalho, situação econômica, atividades realizadas no cotidiano, atividades de lazer e cultura, condição de locomoção, oportunidades de participação comunitária e apoio social.

Os entrevistados foram escolhidos entre aqueles que participavam de um grupo de convivência estruturado após um estudo realizado em 2005 (AOKI; OLIVER; NICOLAU, 2011) que identificou 53 pessoas com deficiência (motoras, intelectuais, visuais, auditivas e deficiências múltiplas), moradoras de uma das áreas de abrangência de uma UBS. Entre essas pessoas, 10 adultos com deficiência participaram do grupo de convivência, organizado em um centro comunitário a partir de março de 2006. Eram 6 mulheres e 4 homens; 5 apresentavam deficiência intelectual; 3, deficiência física; e 2, deficiências múltiplas. Cinco pessoas que representavam o grupo nos quesitos idade, sexo e tipo de deficiência foram escolhidas e aceitaram participar do estudo.

Entre outubro de 2006 e março de 2007, as entrevistas foram realizadas no domicílio, com a pessoa com deficiência e um familiar, que complementava informaçóes sobre aspectos da vida dos entrevistados. Os participantes assinaram termo de consentimento livre e esclarecido, e o estudo foi aprovado pelos Comitês de Ética em Pesquisa da Secretaria Municipal da Saúde de São Paulo e da Faculdade de Medicina da USP.

As entrevistas, gravadas em áudio, foram posteriormente transcritas e analisadas segundo orientaçóes de Bardin (1977) por meio de leituras para exploração e tratamento do material. Foram identificadas as funçóes do discurso, sendo criadas 
hipóteses, como, por exemplo, para o adulto com deficiência, a questão do trabalho seria um tema central? Ou os entrevistados viveriam uma situação de isolamento social? Assim, foi possível identificar os temas mais presentes, os assuntos recorrentes, as singularidades e situações sociais mais gerais, foco das inferências e interpretaçóes.

Para a compreensão e a discussão sobre o modo de vida dos entrevistados, buscou-se conhecer alguns aspectos de seu cotidiano, como: morar, alimentar-se, trabalhar, conversar e passear, categorias discutidas por Kujawski (1991), quando afirma que o homem do século XX vivencia uma crise no cotidiano de forma primária e imediata, em que se rompem as tradiçôes historicamente construídas e o sujeito não reconhece mais seu contexto e sua comunidade e tudo lhe parece estranho e amorfo. Para o autor, a quebra do cotidiano está relacionada à impossibilidade de realizar projetos individuais de vida, por falta de apoio na infraestrutura social, que é a base da articulação organizada do cotidiano. A sensação dos sujeitos é de estranhamento do mundo, insegurança e instabilidade para se pensar no futuro. Essas categorias (morar, alimentar, trabalhar, conversar e passear), também presentes no discurso dos entrevistados, foram utilizadas para a apresentação e discussão dos resultados, à luz de reflexôes sobre necessidades, participação comunitária, acesso a direitos e construção de redes sociais de apoio às pessoas com deficiência. Participaram do estudo:

Marisa (46 anos), mulher que apresenta deficiência física e intelectual, sequelas de encefalopatia crônica não progressiva na infância. Nunca estudou ou trabalhou e recebe o Beneficio de Prestação Continuada. Vive com a irmá (cuidadora) e demanda intensa ajuda dos familiares nas atividades de autocuidado, como alimentação, higiene e vestuário. Gosta de conversar e passear.

Osmar (21 anos), que apresenta deficiência intelectual, percebida no período escolar, quando foi indicada escola especial. Nunca estudou e permanece o dia todo caminhando pelas ruas do bairro à procura de alimentos e trabalho. Não possui renda e é independente nas atividades de autocuidado.

Antonia (54 anos), que foi alcoolista, há 11 anos apresenta sequela de acidente vascular encefálico, resultando em hemiplegia do lado esquerdo. Reside com a filha, com quem divide o único cômodo da casa. Apesar das sequelas motoras, ainda realiza trabalhos informais como faxineira e cuidadora de uma senhora idosa. Sua principal demanda é o acesso ao Benefício de Prestação Continuada.
Adriano (29 anos), que apresenta distrofia muscular progressiva. Sua experiência em educação foi breve, com dificuldades de aprendizado de leitura e escrita. Trabalhou até os 17 anos em fábrica de refrigeradores e atualmente recebe aposentadoria por invalidez. Utiliza cadeira de rodas para se locomover e necessita da ajuda da mãe idosa para as tarefas do cotidiano. Gosta de realizar atividades artísticas, artesanais e de passear.

Rosa (45 anos), que apresenta hemiplegia em decorrência de encefalopatia crônica não progressiva na infância e ainda sofre convulsóes (epilepsia). Concluiu o ensino médio e trabalhou como faxineira e cuidadora em creche. Atualmente recebe aposentadoria por invalidez. Apresenta lentidão motora e psíquica, relacionada possivelmente ao uso de anticonvulsivantes e antipsicóticos. Vive sozinha em um apartamento e sua principal queixa é a solidão.

\section{Resultados}

Os entrevistados revelaram que a necessidade de assistência em saúde e reabilitação sempre foi uma questáo importante em suas vidas. Adriano, durante a infância, procurou atendimento em saúde, pois não aprendia a ler e escrever e, quando jovem, peregrinou por serviços de saúde em busca de um diagnóstico médico, só esclarecido por iniciativa da UBS, aos 27 anos. Aguardava acompanhamento de hidroterapia em lista de espera de serviço público. Antonia também nunca realizou tratamento em reabilitação e frequentemente procurava a UBS, pois seus pés estavam sempre edemaciados e a hipertensão arterial, descompensada. Rosa tinha sua rotina de cuidados restrita às consultas médicas; nunca realizou tratamento em reabilitação ou em outra especialidade não médica. Embora todos conhecessem, necessitassem e desejassem esse tipo de assistência, não puderam usufruir dessa possibilidade.

Outra dimensão das necessidades estava relacionada ao trabalho, uma das esferas mais importantes da vida cotidiana. Com exceção de Marisa, que nunca realizou atividade remunerada, o trabalho foi um tema de relevância para os entrevistados. Antonia foi cuidadora de idosos em asilo; Rosa, faxineira e trabalhadora em creche, e Adriano trabalhou em linha de montagem de refrigeradores; para ele, porém, esse trabalho era "muito pesado". A manifestação da deficiência, condição enfrentada por esses três entrevistados, levou-os ao afastamento do trabalho, o que gerou sofrimento e acentuou um sentimento de desvalorização social. Nos casos de Antonia, Rosa e Adriano, o processo de ruptura com o trabalho foi 
efetivo e a retomada da vida cotidiana ocorreu de modo singular, segundo as habilidades remanescentes, a aquisição de benefícios previdenciários e o apoio familiar e social, com que contaram para reestruturar o cotidiano. Já para Osmar, jovem com deficiência intelectual que realizava pequenos serviços no bairro, esse trabalho também era central em sua vida, porém realizado com contradiçóes e conflitos, devido ao seu caráter informal e às condiçôes sociais e cognitivas do rapaz.

Antonia tinha a necessidade urgente de acessar o Benefício de Prestação Continuada, o que vinha sendo postergado e dificultado por mecanismos burocráticos, que obstaculizavam a garantia desse direito social.

Além de possuírem a condição da deficiência, os entrevistados também compartilhavam semelhante situação de pobreza e restrita participação comunitária. A urgência da sobrevivência diária ficou evidente nos discursos, sendo alimento e moradia as prioridades do cotidiano. Osmar, durante a entrevista, reiterou o pedido por alimentos, o que sugeria a precariedade de suas condiçôes de vida. Adriano revelou o descontentamento com relaçáo à sua moradia, inacessível para cadeira de rodas. A demanda por uma moradia isenta de barreiras arquitetônicas era uma necessidade urgente para ele e a reforma da casa estava no rol das prioridades de sua vida. Em outras dimensões, a questão da precariedade das condiçóes de moradia também estava presente para Antonia, que habitava um único cômodo e pagava aluguel, e para Osmar, que dividia com sete irmãos os escassos recursos da casa, ou, ainda, para Rosa, que vivia restrita ao quarto do apartamento onde morava.

Nas entrevistas, os participantes também falaram sobre o prazer que vivenciavam ao manter uma conversa, porém relataram que o bate-papo, o encontro com amigos, parentes, vizinhos e a troca de experiências eram momentos raros em suas vidas. Embora se mostrassem desejosos de manter relaçóes sociais e afetivas, o que prevalecia era o isolamento domiciliar e a convivência restrita ao ambiente familiar.

Osmar verbalizou "sempre andar sozinho" e "não possuir amigos". Como disse sua máe, "[...] a Cohab [bairro em que mora] inteirinha conhece ele! Você pode perguntar pra qualquer um quem é o Osmar." Assim, Osmar vive uma contradição: "o pessoal aqui adora ele”, porém ele está sempre sozinho. O lugar social reservado para alguns deficientes intelectuais é marcado pela proteção, exploração de sua força de trabalho, infantilização e percepção equivocada de que não são capazes de realizar trocas sociais e afetivas.
Já Rosa, ao refletir sobre as razões de seu isolamento, focou-se em suas próprias incapacidades e características (caminhar com dificuldades e fumar), porém pouco questionou as condições sociais e ambientais que a distanciavam dos familiares e que poderiam auxiliá-la no enfrentamento desses impedimentos. Para ela, o isolamento era uma questáo crucial em sua vida: "[...] quem pensa que é o cigarro que me mata, não é! É a prisão da casa." Assim, denunciou a solidão e o ócio como situaçôes que a fazem sofrer.

Nesse cenário, são escassas as situaçóes de lazer e passeios, que, embora desejadas pelos entrevistados, são momentos raros em suas vidas. As oportunidades de sair de casa e os passeios comunitários realizados foram recordados como momentos de prazer, satisfação, aprendizado e intensificação das relaçōes sociais. Antonia comentou com alegria que pode passear, pois "de repente, eles me deram a passagem", como uma situação de privilégio. Lembrou-se de que comeu bastante, indicando a importância da alimentação quando se vive a condição de escassez de comida. Marisa contou com empolgação as atividades que realizava na UBS e na comunidade: durante a semana, participava de dois grupos de convivência e, mensalmente, frequentava reunióes do Conselho Municipal da Pessoa com Deficiência de São Paulo. Adriano, por sua vez, teve oportunidade de visitar o Zoológico e conhecer o Parque do Ibirapuera. Verbalizou que desejava conversar, passear e namorar, e ressaltou, positivamente, as oportunidades de lazer e compromissos sociais dos quais participou, mostrando-se motivado a projetar e demandar mais oportunidades; desejava conhecer novos lugares, não se contentando mais em somente observá-los através da televisão. Também identificou a falta de transporte adequado e de apoio social para se deslocar, como as principais questóes que o impediam de circular pelo bairro e pela cidade. É a mãe, idosa, a responsável pelo cuidado e locomoção do filho, o que reduz sua possibilidade de participaçáo e fruição das oportunidades.

Assim, a dependência de um familiar para a manutenção da própria vida apareceu com destaque e as cuidadoras (filhas, irmãs, mães) de pessoas com deficiências graves também demandaram atenção, escuta e busca de alternativas de intervenção, a fim de amenizar a condição de sofrimento de quem provê apoio e cuidados diários e permanentes.

\section{Discussão}

As necessidades no campo da saúde e reabilitação sempre estiveram presentes para as pessoas entrevistadas, possibilidades de não agravamento 
das condiçóes de incapacidade, necessidades legítimas, muitas vezes negadas, especialmente pela dificuldade de acesso a serviços.

Sobre o tema, Castro et al. (2011) discutem os problemas enfrentados pelas pessoas com deficiência para a acessibilidade aos serviços de saúde (demora de atendimento, falta de rampas, elevadores, cadeiras de rodas, profissionais qualificados), o que impede a equidade, preceito do SUS. Othero (2010) também enfatizou a localização geográfica dos serviços (quase sempre situados nas áreas centrais da cidade), sua baixa capacidade de realizar atendimentos, bem como as péssimas condições urbanas de acessibilidade.

As experiências de assistência em saúde relatadas auxiliam a reflexão sobre as respostas dos serviços de saúde e reabilitação às demandas dos sujeitos, respostas tardias e incompletas, muitas vezes focadas no atendimento médico clínico, que apaziguam apenas parcialmente as carências das pessoas com deficiências e de suas famílias. Pela atual organização dos serviços, essas são as respostas possíveis de serem geradas, o que novamente nos faz pensar em contextos instauradores de necessidades (SCHRAIBER; MENDES-GONÇALVES, 1996), como é o caso dos serviços tradicionais de reabilitação.

Assim, entende-se que as pessoas com deficiência entrevistadas, caracterizadas pela cronicidade da condição da deficiência e incapacidade, não têm a garantia de acesso à tecnologia para manutençáo e prolongamento da vida com qualidade, um dos aspectos fundamentais levantados por Cecílio (2001) em suas reflexóes sobre necessidades de saúde.

Por outro lado, o tema trabalho, essencial para a reprodução social, tem grande relevância na vida dos entrevistados, que, ao narrarem suas atividades profissionais, relataram as contradições presentes nesse campo. Suas experiências dizem respeito às oportunidades de inclusão no trabalho, colocadas pela atual conjuntura econômica, social e política, em que o ambiente de trabalho tem sido extremamente precário, induz a competitividade entre os trabalhadores produzindo poucas relaçóes de solidariedade e invade todos os espaços da vida do sujeito, o que inclusive pode modificar a formação do caráter (SENNET, 2008).

Nesse sentido, como discutiu Castel (1994), os entrevistados, ao vivenciarem a condição do desemprego ou da precariedade do trabalho, apresentam uma posição de intensa vulnerabilidade caracterizada pela pobreza, pela falta do trabalho e também pela limitação das relaçóes sociofamiliares, parte de um processo de desfiliação social. Embora o trabalho tenha sido abordado como possibilidade de participação social e de sobrevivência, as experiências dos entrevistados também o indicavam como fonte de sofrimento, alienação e adoecimento.

Alimentação, moradia e locomoção estáo entre as necessidades relacionadas às condiçôes de vida e à possibilidade de viver com autonomia. A necessidade de ter boas condiçôes de vida (CECÍLIO, 2001) é parte do reconhecimento de que o lugar que o sujeito ocupa no processo produtivo auxilia a compreensáo dos modos de adoecer e viver, e que a vida pode se tornar frágil e inviável, apontando um abismo entre as experiências cotidianas desses sujeitos e o exercício da cidadania.

A aquisição de alimento e o pagamento de aluguel são prioridades para a sobrevivência dos entrevistados, que vivem em condiçóes semelhantes às dos demais moradores de bairros periféricos $\mathrm{da}$ cidade. Porém as condições de vida, o acesso a bens materiais e serviços é mais restrito dada a situação da deficiência e sua estreita relação com a pobreza (SOUZA; CARNEIRO, 2009). Há dificuldade de geração de renda, pois a dependência das pessoas com deficiência pode acarretar, também, no impedimento do cuidador de realizar uma atividade profissional.

Por outro lado, é no âmbito do passear que, para Kujawski (1991), se dá a possibilidade de estar efetivamente na cidade, apropriar-se dela. Os espaços passam a ter um valor e um significado singular, dáo contorno e identidade ao sujeito. Para esse autor, a possibilidade de conversar é considerada a ocupação mais deleitosa e fecunda do cotidiano, permitindo o reconhecimento das pessoas entre si, a troca de experiências, o conhecimento de outras perspectivas e realidades, além de promover sujeitos mais criativos e livres.

Embora passear e conversar fossem atividades desejadas pelos entrevistados, o que prevaleceu foi a condição de isolamento social, em que são raras as oportunidades de participação comunitária.

Quais situaçôes corroboraram para a manutenção desse isolamento? Segundo os entrevistados e seus familiares, os obstáculos presentes na vida dessas pessoas, a intolerância à diferença, a valorização do individual em detrimento do coletivo, as diferentes formas de estruturação familiar contemporânea, a falta de acessibilidade e transporte adequado para pessoas com deficiência, a fragilidade das relaçôes de solidariedade e a própria condição de confinamento produzem sujeitos fragilizados e com muita dificuldade para estar no convívio social.

O estudo, ao ter considerado o ambiente familiar e comunitário, também revelou demandas e necessidades de apoio aos familiares, pelas restritas 
oportunidades de receberem auxílio de vizinhos, amigos e serviços. Os cuidadores eram todos do sexo feminino, sendo premente a necessidade de fortalecer e ampliar essa rede e de realizar intervençóes que amenizassem o sofrimento físico e psíquico dos envolvidos no cuidado à pessoa com deficiência. Outros estudos também indicaram a importância desse tema (AZEVEDO; SANTOS, 2006; BOCCHI; ANGELO, 2008) ao discutirem as experiências de cuidadores de pessoas que passaram por processos de reabilitação e enfatizam a importância do apoio social. Em ambos os estudos, discute-se a condição de sofrimento do cuidador e as estratégias possíveis para transformar tal situação a partir de maior investimento econômico familiar (exemplo: contratação de um cuidador formal), da existência de suporte tecnoinstitucional e do aumento da rede de apoio.

Os entrevistados que possuíam uma rede de apoio mais ativa com familiares e pessoas da comunidade sentiam-se mais amparados, o que pode significar que a existência de uma rede de apoio social intensa e efetiva atue positivamente na saúde dos sujeitos, e que situaçóes como a existência de doenças crônicas e deficiências podem gerar a retração dessas redes (SLUZKI, 1997).

A necessidade de criação de vínculos (a)efetivos entre usuário e uma equipe e/ou profissional bem como a necessidade de cada pessoa ter graus crescentes de autonomia no seu modo de levar a vida (CECÍLIO, 2001) foram questóes presentes nos depoimentos. $\mathrm{O}$ estudo promoveu a escuta de pessoas com poucas oportunidades de realizar escolhas e participaçáo. A UBS tem feito parte da rede de apoio social dos entrevistados pelas estratégias de escuta e intervenção criadas a partir das necessidades colocadas por essa população.

O estudo possibilitou considerar que necessidades de saúde são também necessidades de presença do Estado, para garantia de serviços que promovam o bem-estar social e a regulaçáo entre capital e trabalho, reduzindo as diferenças sociais e o acesso aos direitos de cidadania (CAMPOS; MISHIMA, 2005). A seguridade social, com atuação mínima em nosso país, tem estado presente na vida cotidiana das pessoas com deficiência por meio da concessão de aposentadorias e benefícios, como passe livre de ônibus, transporte municipal adaptado, concessão de equipamentos (cadeiras de rodas, entre outros), além da insuficiente assistência à saúde e reabilitaçáo. Para o enfrentamento da condição apresentada, é fundamental a presença mais efetiva do Estado no âmbito de uma seguridade social articulada com possibilidades de apoiar as pessoas com deficiência e suas famílias.

Para um dos entrevistados, a necessidade de participação politica (CAMPOS; MISHIMA, 2005) se efetivava através da participação em um conselho de defesa de direitos das pessoas com deficiência, o que tem contribuído para o seu reconhecimento enquanto sujeito de direitos e, coletivamente, para dar visibilidade às questóes vivenciadas por essa população.

\section{Considerações finais}

Estudos sobre as necessidades das pessoas com deficiência têm sido fundamentais para reflexão, proposição, discussão e avaliação de estratégias alternativas de atenção entre profissionais de saúde e reabilitação.

Os entrevistados participantes desta pesquisa desejavam passear e conversar, ter uma moradia digna e aconchegante, alimento, trabalho, benefício previdenciário, locomover-se e realizar tratamento em reabilitação, necessidades relacionadas à garantia de direitos sociais, de condiçâo de vida digna e com maior grau de autonomia.

A complexidade das necessidades apresentadas pelos entrevistados exige a implementação de políticas públicas para produção de intervenções que ampliem as redes de apoio social, o acesso às informações e a articulação de açóes intersetoriais para minimização de processos de exclusão e de desfiliaçáo social. Os serviços de saúde, principalmente aqueles de atenção primária, têm desafios e responsabilidades na promoção da escuta e acolhimento das demandas e necessidades dessa população para a criação de alternativas assistenciais em que a promoção da participação comunitária e o acesso a direitos fundamentais sejam também ferramentas para o trabalho assistencial.

\section{Referências}

AOKI, M.; OLIVER F. C.; NICOLAU, S. M. Consideraçōes acerca das condições de vida das pessoas com deficiência a partir de um levantamento em uma unidade básica de saúde de um bairro periférico do município de São Paulo. O Mundo da Saúde, São Paulo, v. 35, n. 2, p. 169-178, 2011. Disponível em: <http:// www.saocamilo-sp.br/pdf/mundo_saude/84/169-178. pdf $>$. Acesso em: 12 jul. 2012.

AOKI, M. Reabilitação com ênfase no território: demandas das pessoas com deficiência e participação comunitária. 2009. 190 f. Dissertaçáo (Mestrado em Ciências)-Faculdade de Medicina, Universidade de São Paulo, 2009. 
AZEVEDO, G. R.; SANTOS, V. L. C. G. Cuida-dor (d)eficiente: as representaçóes sociais de familiares acerca do processo de cuidar. Revista Latino-Americana de Enfermagem, Ribeirão Preto, v. 14, n. 5, p. 770-80, 2006. http://dx.doi.org/10.1590/S0104-11692006000500020 BARDIN, L. Análise de conteúdo. Lisboa: Ediçōes 70, 1977. BAXTER, H. et al. Previously unidentified morbidity in patients with intellectual disability. British Journal of General Practice, London, v. 56, p. 93-98, 2006. Disponível em: <http://www.ncbi.nlm.nih.gov/pmc/articles/ PMC1828252/pdf/bjpg56-93.pdf?tool=pmcentrez>. Acesso em: 09 nov. 2011.

BOCCHI, S. C. M.; ANGELO, M. Entre a liberdade e a reclusão: o apoio social como componente da qualidade de vida do binômio cuidador familiar-pessoa dependente. Revista Latino-Americana de Enfermagem, Ribeirão Preto, v. 16, n. 1, p. 15-23, 2008. http://dx.doi.org/10.1590/ S0104-11692008000100003

BRASIL. Ministério da Saúde. Secretaria de Atenção à Saúde. Departamento de Atençáo Básica. Diretrizes do Nasf: Núcleo de Apoio a Saúde da Família. Brasília: Ministério da Saúde, 2010. (Cadernos da atençáo básica).

BRASIL. Ministério da Saúde. Portaria no 793, de 24 de abril de 2012. Institui a Rede de Cuidados à Pessoa com Deficiência no âmbito do Sistema Único de Saúde. Diário Oficial da República Federativa do Brasil, Brasília, DF, 25 abr. 2012. Seção 1. Disponível em: <http://bvsms.saude. gov.br/bvs/saudelegis/gm/2012/prt0793_24_04_2012. html>. Acesso em: 22 ago. 2012.

CAMPOS, C. M. S.; MISHIMA, S. M. Necessidades de saúde na voz da sociedade civil e do estado. Cadernos de Saúde Pública, Rio de Janeiro, v. 21, n. 4, p. 1260-1268, 2005. http://dx.doi.org/10.1590/ S0102-311X2005000400029

CAMPOS, C. M. S.; BATAIERO, M. O. Necessidades de saúde: uma analise de produçáo científica de 1990 a 2004. Interface: Comunicação, Saúde, Educação, Botucatu, v. 11, n. 23, p. 605-618, 2007. http://dx.doi. org/10.1590/S1414-32832007000300014

CASTEL, R. Da indigência à exclusão, a desfiliação precariedade do trabalho e vulnerabilidade relacional. In: LANCETTI, A. Saúde e Loucura, 4. Grupos e Coletivos. São Paulo: Hucitec, 1994. p. 21-48.

CASTRO, S. S. et al. Acessibilidade aos serviços de saúde por pessoas com deficiência. Revista de Saúde Pública, São Paulo, v. 45, n. 1, p. 99-105, 2011. http://dx.doi. org/10.1590/S0034-89102010005000048

CECÍLIO, L. C. O. As necessidades de saúde como conceito estruturante na luta pela integralidade e equidade na atenção em saúde. In: PINHEIRO, R.; MATOS, R. A. (Org.). Os sentidos da integralidade na atenção e no cuidado à saúde. Rio de Janeiro: IMS/UERJ, 2001. p. 113-26.

EASTGATE, G.; LENNOX, N. G. Primary health care for adults with intellectual disability.
Australian Family Physician, Melbourne, v. 32, n. 5, p. 330-33, 2003. Disponível em: <http://www.racgp. org.au/afp/200305/20030501eastgate.pdf $>$. Acesso em: 12 nov. 2011.

EGRY, Y.; OLIVEIRA, M. A. C. Marcos teóricos e conceituais de necessidades. In: EGRY, Y. (Org.). As necessidades em saúde na perspectiva de atenção básica: Guia para pesquisadores. São Paulo: Dedone, 2008. v. 1, p. 31-38.

JANG, S. N. et al. The continuum of rehabilitation care and the rehabilitation services that are needed by people with severe disabilities. Journal of Preventive Medicine and Public Health, Seoul, v. 39, n. 3, p. 263-269, 2006. Disponível em: $<$ http://komci.org/GSResult.php?RID= 1056JPMPH\%2F2006.39.3.263\&DT=1\&ITEMNO=4 29\&TITEM=1204>. Acesso em: d10 nov. 2011.

KUJAWSKI, G. M. Crise do século XX. 2. ed. São Paulo: Ática, 1991.

OTHERO, M. B.; DALMASO, A. S. W. Pessoas com deficiência na atenção primária: discurso e prática de profissionais em um centro de saúde-escola. Interface: Comunicação, Saúde, Educação, Botucatu, v. 13, n. 28 , p. $177-188,2009$. http://dx.doi.org/10.1590/ S1414-32832009000100015

OTHERO, M. B. Atenção à saúde da pessoa com deficiência: necessidades sob a perspectiva dos sujeitos. 2010. $331 \mathrm{f}$. Dissertaçáo (Mestrado em Medicina Preventiva)-Faculdade de Medicina, Universidade de São Paulo, 2010.

PEDUZZI, M.; SCHRAIBER, L. B. Processo de trabalho em saúde. In: PEREIRA, I. B.; LIMA, J. C. F. (Org.). Dicionário da Educação Profissional em Saúde. 2. ed. Rio de Janeiro: Escola Politécnica de Saúde São Venâncio, Fiocruz, Ministério da Saúde, 2009. p. 320-28.

ROCHA, E. F.; SOUZA, C. C. B. X. Terapia ocupacional em reabilitaçáo na atençáo primaria a saúde: possibilidades e desafios. Revista de Terapia Ocupacional da USP, São Paulo, v. 22, n. 1, p. 36-44, 2011. Disponível em: <http:// www.revistasusp.sibi.usp.br/pdf/rto/v22n1/06.pdf>. Acesso em: 01 abril 2012.

SCHRAIBER, L. B.; MENDES-GONÇALVES R. B. Necessidades de saúde e atenção primária. In: SCHRAIBER, L. B.; NEMES, M. I. B.; MENDESGONÇALVES, R. B. Saúde do adulto: programas e ações na unidade básica. São Paulo: Hucitec, 1996. p. 29-47.

SENNET, R. A corrosão do caráter: as conseqüências pessoais do trabalho no novo capitalismo. 13. ed. Rio de Janeiro: Record, 2008.

SLUZKI, C. E. A rede social na prática sistêmica: alternativas terapêuticas. São Paulo: Casa do Psicólogo, 1997.

SOUZA, J. M.; CARNEIRO, R. Universalismo e focalização na política de atenção à pessoa com deficiência. Saúde Sociedade, São Paulo, v. 16, n. 3, p. 69-84, 2009. http://dx.doi.org/10.1590/S0104-12902007000300007

\section{Contribuição dos Autores}

Marta Aoki: concepção do manuscrito, responsável pela pesquisa, redação e revisão do texto. Fátima Correa Oliver: orientou a pesquisa, apoiou a elaboração e revisão do manuscrito. 